\title{
Lung-kidney cross-talk in the critically ill: insights from the Lung Safe study
}

\author{
E. Rezoagli ${ }^{1,2}$, B. McNicholas ${ }^{2,3}$, T. Pham ${ }^{4,5,6}$, G. Bellani ${ }^{1,7}$ and J. G. Laffey ${ }^{2,4,8^{*}}$
}

๑) 2020 Springer-Verlag GmbH Germany, part of Springer Nature

\section{Dear Editor,}

We read with interest the consensus report on lung-kidney 'cross-talk' in the critically ill by Joannidis and colleagues arising from the 2018 Acute Disease Quality Initiative (ADQI 21) workshop [1]. The report identified key knowledge gaps in our understanding of the mechanisms underlying lung-kidney cross-talk and prioritised research initiatives to address these gaps [1].

Since the AQDI conference, we published a secondary analysis of the LUNG SAFE study [2], which found that even mild-moderate AKI was associated with a substantial increase in mortality, highlighting the importance of these issues [3]. We wish to highlight some insights from that analysis, and provide additional analyses regarding the role of lung-kidney cross-talk as an injury mechanism [3].

In the LUNG SAFE Cohort, AKI and ARDS generally developed contemporaneously rather than sequentially. AKI occurred at or within $48 \mathrm{~h}$ of ARDS development in 765 (39\%) of 1974 ARDS patients, with a further 4.3\% developing AKI on days 3-7 of ARDS. Of the 228 AKI patients (30\%) that received RRT, $62 \%$ commenced within 48 h, 29\% between days 3 and 7, and 9\% between days 8 and 28 following ARDS development. Reassuringly, the impact of AKI on the ventilatory management of patients with ARDS appeared limited. Specifically, despite the presence of acidosis in patients with AKI, there were no differences in arterial $\mathrm{CO}_{2}$ tension, or in tidal or minute ventilation between the groups. While our data do not exclude the potential for an impact of AKI on lung

\footnotetext{
*Correspondence: john.laffey@nuigalway.ie

${ }^{2}$ Regenerative Medicine Institute (REMEDI) at CÚRAM Centre for Research in Medical Devices, Biomedical Sciences Building, National University of Ireland Galway, Galway, Ireland

Full author information is available at the end of the article
}

function, it does appear that 'protective' ventilatory strategies were prioritized over attempts to compensate for $\mathrm{pH}$ status.

A multivariate analysis of risk factors for early AKI (i.e. in the two first days of ARDS) in patients with ARDS suggests that the impact of ARDS on the development of AKI was limited (Table 1). Specifically, no association was found between ventilatory variables (i.e. tidal volume, total respiratory rate, $\mathrm{FIO}_{2}$, PEEP,) or indices of lung injury severity (i.e. peak inspiratory pressure and $\mathrm{PaO}_{2} /$ $\mathrm{FiO}_{2}$ ) and the presence of AKI. Of importance, this analysis identified known 'ARDS risk factors' such as sepsis [4], non-cardiogenic shock, TRALI and pancreatitis, as independent risk factors for AKI. The presence of shock was also associated with AKI development. This analysis suggests that these factors constitute common underlying injury mechanisms that drive the concomitant development of organ failures, including AKI and ARDS, in the critically ill.

In conclusion, the spatio-temporal relationships regarding acute lung and kidney failure in the critically ill remain poorly understood [5]. In the LUNG SAFE cohort, AKI and ARDS frequently evolved contemporaneously and early in the course of critical illness, likely driven by common underlying pathophysiologic processes. Our findings did not support a central role for lung-kidney 'cross talk' in mediating early AKI in patients with ARDS, with no evidence that the presence of AKI impacted ARDS management, or that the ventilatory management or ARDS severity was associated with risk of AKI development. These findings do not preclude a role for lungkidney cross-talk in the development of AKI later in the course of ARDS, or for ARDS to negatively impact the resolution of AKI. A better understanding of the roles of shared underlying risk factors such as sepsis, the overall severity of critical illness, hemodynamic instability and

\section{Springer}


Table 1 Multivariate analysis of factors associated with early AKI in our ARDS population

\begin{tabular}{|c|c|c|c|}
\hline Variable & OR & $95 \% \mathrm{Cl}$ & $P$ value \\
\hline \multicolumn{4}{|l|}{ Baseline characteristics } \\
\hline Age (years) & 1.02 & $1.01-1.03$ & $<0.001$ \\
\hline Male (Ref. female) & 1.53 & $1.21-1.93$ & $<0.001$ \\
\hline $\mathrm{BMI}\left(\mathrm{kg} / \mathrm{m}^{2}\right)$ & 1.03 & $1.01-1.04$ & 0.001 \\
\hline \multicolumn{4}{|l|}{ IIIness severity (day 1 of ARDS) } \\
\hline SOFA score-Cardiovascular & 1.28 & $1.20-1.37$ & $<0.001$ \\
\hline \multicolumn{4}{|l|}{ Risk factors of ARDS } \\
\hline Sepsis (Ref. No) & 1.96 & $1.46-2.64$ & $<0.001$ \\
\hline Non-cardiogenic shock (Ref. No) & 1.82 & $1.23-2.69$ & 0.003 \\
\hline TRALI (Ref. No) & 2.42 & $1.43-4.09$ & 0.001 \\
\hline Pancreatitis (Ref. No) & 2.46 & $1.17-5.20$ & 0.018 \\
\hline \multicolumn{4}{|l|}{ Comorbidities } \\
\hline Diabetes (Ref. No) & 1.43 & $1.08-1.90$ & 0.013 \\
\hline Chronic liver failure (Ref. No) & 1.93 & $1.12-3.33$ & 0.018 \\
\hline COPD (Ref. No) & 0.54 & $0.40-0.72$ & $<0.001$ \\
\hline \multicolumn{4}{|l|}{ Metabolic variables (day 1 of ARDS) } \\
\hline pH (per 0.01 increase) & 0.94 & $0.93-0.95$ & $<0.001$ \\
\hline \multicolumn{4}{|l|}{ Other } \\
\hline Medical admission (Ref. No) & 1.58 & $1.21-2.07$ & 0.001 \\
\hline
\end{tabular}

Variables with a $P$ value $<0.20$ at the univariate analysis were included into a multivariable logistic regression model using a stepwise selection approach. Statistical significance was considered with a $P$ value $<0.05$ (two-tailed). No ventilator variables (i.e. tidal volume per predicted body weight, total respiratory rate, peak inspiratory pressure, $\mathrm{PEEP}, \mathrm{PaO}_{2} / \mathrm{FiO}_{2}$ and $\mathrm{FIO}_{2}$ ) selected at the univariate analysis was significant in the multivariate model $n=1765$

$B M I$ body mass index, SOFA sequential organ failure assessment, TRALI transfusion related acute lung injury, COPD chronic obstructive pulmonary disease

of Lung-Kidney 'cross-talk' is essential to improving outcomes in these patients.

\section{Author details}

${ }^{1}$ School of Medicine and Surgery, University of Milano - Bicocca, Monza, Italy. ${ }^{2}$ Regenerative Medicine Institute (REMEDI) at CÚRAM Centre for Research in Medical Devices, Biomedical Sciences Building, National University of Ireland Galway, Galway, Ireland. ${ }^{3}$ Nephrology, School of Medicine, National University of Ireland Galway, Galway, Ireland. ${ }^{4}$ Keenan Research Centre for Biomedical Science, St Michael's Hospital, Toronto, Canada. ${ }^{5}$ Interdepartmental Division of Critical Care Medicine, University of Toronto, Toronto, Canada.

${ }^{6}$ Service de médecine Intensive-réanimation, AP-HP, Hôpital de Bicêtre,
Hôpitaux Universitaires Paris-Saclay, Le Kremlin-Bicêtre, France. ${ }^{7}$ Department of Emergency and Intensive Care, San Gerardo Hospital, Monza, Italy. ${ }^{8}$ Anaesthesia and Intensive Care Medicine, School of Medicine, National University of Ireland Galway, Galway, Ireland.

\section{Funding}

This work was funded and supported by the European Society of Intensive Care Medicine (ESICM), Brussels, Belgium, by St Michael's Hospital, Toronto, Canada, and by the University of Milano - Bicocca, Monza, Italy.

Role of the funders: The ESICM provided support in data collection and study coordination. ESICM, St Michael's Hospital, and University of Milano Bicocca had no role in the design and conduct of the study; management, analysis, and interpretation of the data; preparation, review, or approval of the manuscript; or decision to submit the manuscript for publication.

\section{Compliance with ethical standards}

\section{Conflicts of interest}

The authors attest that they have no conflicts of interest in regard to the subject of this manuscript.

\section{Publisher's Note}

Springer Nature remains neutral with regard to jurisdictional claims in published maps and institutional affiliations.

\section{Accepted: 6 February 2020}

Published online: 24 February 2020

\section{References}

1. Joannidis M, Forni LG, Klein SJ, Honore PM, Kashani K, Ostermann M, Prowle J, Bagshaw SM, Cantaluppi V, Darmon M, Ding X, Fuhrmann V, Hoste E, Husain-Syed F, Lubnow M, Maggiorini M, Meersch M, Murray PT, Ricci Z, Singbartl K, Staudinger T, Welte T, Ronco C, Kellum JA (2019) Lung-Kidney interactions in critically ill patients: consensus report of the acute disease quality initiative (adqi) 21 workgroup. Intensive Care Med 9:1-9

2. Bellani G, Laffey JG, Pham T, Fan F, Brochard L, Esteban A, Gattinoni L, van Haren F, Larsson A, McAuley DF, Ranieri M, Rubenfeld GD, Thompson BT, Wrigge H, Slutsky AS, Pesenti A, LUNG SAFE Investigators, and ESIM Trials Group (2016) Epidemiology, patterns of care, and mortality for patients with acute respiratory distress syndrome in intensive care units in 50 countries. JAMA 315:788-800

3. McNicholas BA, Rezoagli E, Pham T, Madotto F, Guiard E, Fanelli V, Bellani G, Griffin MD, Ranieri M, Laffey JG, LUNG SAFE Investigators, and ESIM Trials Group (2019) Impact of early acute kidney injury on management and outcome in patients with acute respiratory distress syndrome: a secondary analysis of a multicenter observational study. Crit Care Med 47:1216-1225

4. Bellomo R, Kellum JA, Ronco C, Wald R, Martensson J, Maiden M, Bagshaw SM, Glassford NJ, Lankadeva Y, Vaara ST, Schneider A (2017) Acute kidney injury in sepsis. Intensive Care Med 43:816-828

5. Doig GS, Mcllroy DR (2019) Acute kidney injury in patients with acute respiratory distress syndrome: the chicken or the egg? Crit Care Med 47:1273-1274 